\title{
Midline Cerebellar Medulloblastoma in a Seventy-One-Year-Old Patient
}

\author{
Raymund L. Yong, Eoin C. Kavanagh, David Fenton, Katerina Dorovini-Zis, \\ Manraj K.S. Heran, Charles S. Haw
}

\begin{abstract}
Background: Medulloblastoma is the most common malignant central nervous system tumour in children but, in contrast, quite rare in adults. Hemispheric, rather than midline, cerebellar medulloblastomas are more common in older children and adults. We present the unusual case of a 71-year-old man who presented with a fourth ventricular mass that proved to be a medulloblastoma. Methods: A 71-year-old man presented with progressive balance problems, slurred speech and double vision. A CT scan of the brain revealed a hyperattenuating, partially calcified, avidly enhancing mass within the fourth ventricle. Diffusion weighted MRI showed restricted diffusion within the mass. The patient underwent a midline suboccipital craniotomy and a subtotal resection was achieved. Results: Histological examination showed a densely cellular neoplasm composed of small cells with a tendency towards neuroblastic rosette formation. Most cells were strongly positive for neuron-specific enolase and synaptophysin. Ultrastructurally, tumour cells showed evidence of neuronal differentiation. These findings were consistent with a classical medulloblastoma. Conclusion: Adult medulloblastoma should be considered in the differential diagnosis of a partially calcified hyperattenuating mass within the fourth ventricle.
\end{abstract}

RÉSUMÉ: Médulloblastome cérébelleux médian chez un patient âgé de soixante-onze ans. Contexte: Le médulloblastome est la tumeur maligne la plus fréquente du système nerveux central chez les enfants. Il est cependant rare chez les adultes. Le médulloblastome cérébelleux hémisphérique plutôt que médian est plus fréquent chez les enfants plus vieux et chez les adultes. Nous présentons un cas rare, celui d'un homme âgé de 71 ans, qui présentait une masse identifiée comme étant un médulloblastome dans le quatrième ventricule. Méthodes: Un homme de 71 ans a consulté pour une ataxie, une dysarthrie et une diplopie progressives. La tomodensitométrie cérébrale a montré une masse très atténuante, partiellement calcifiée et très rehaussante, dans le quatrième ventricule. L'IRM de diffusion pondérée a révélé une diffusion restreinte à l'intérieur de la masse. Le patient a subi une craniotomie sous-occipitale médiane et une résection subtotale de la tumeur. Résultats: L'examen anatomopathologique a montré qu'il s'agissait d'une néoplasie à haute densité cellulaire composée de petites cellules qui avaient tendance à former des rosettes neuroblastiques. La plupart des cellules tumorales étaient fortement positives pour la neuro specific enolase et la synaptophysine. À la microscopie électronique, les cellules tumorales présentaient des signes de différenciation neuronale. On a posé un diagnostic de médulloblastome classique. Conclusion: Le médulloblastome devrait faire partie du diagnostic différentiel d'une masse hyperatténuante, partiellement calcifiée, à l'intérieur du quatrième ventricule chez l'adulte.

Can. J. Neurol. Sci. 2006; 33: 101-104

Medulloblastoma is the most common malignant central nervous system tumour in children. Ninety-four percent of medulloblastomas arise within the cerebellum with approximately $3 \%$ arising within the fourth ventricle. ${ }^{1}$ In contrast, medulloblastomas are rare in adults, representing 0.4 to $1 \%$ of all central nervous system tumours. ${ }^{1}$ Hemispheric, rather than midline, cerebellar medulloblastomas are more common in older children and adults. ${ }^{2}$ We present the unusual case of a 71-yearold man who presented with a partially calcified hyperattenuating mass within the fourth ventricle that was pathologically proven to be a medulloblastoma.

\section{Case Report}

A 71-year-old man sought medical attention for a two-month history of progressive problems with balance, slurred speech and double vision.

From the Division of Neurosurgery, Department of Surgery (RLY, CSH); Department of Radiology (ECK, DF, MKSH); Department of Pathology (KDZ); University of British Columbia, Vancouver, BC, Canada.

ReCEIVED APRIL 18, 2005. ACCEPTED IN FINAL FORM August 27, 2005. Reprint requests to: Raymund Lee-Ming Yong, Division of Neurosurgery, Department of Surgery, University of British Columbia, 3100 - 910 West 10th Avenue, Vancouver, British Columbia, V5Z 4E3, Canada. 

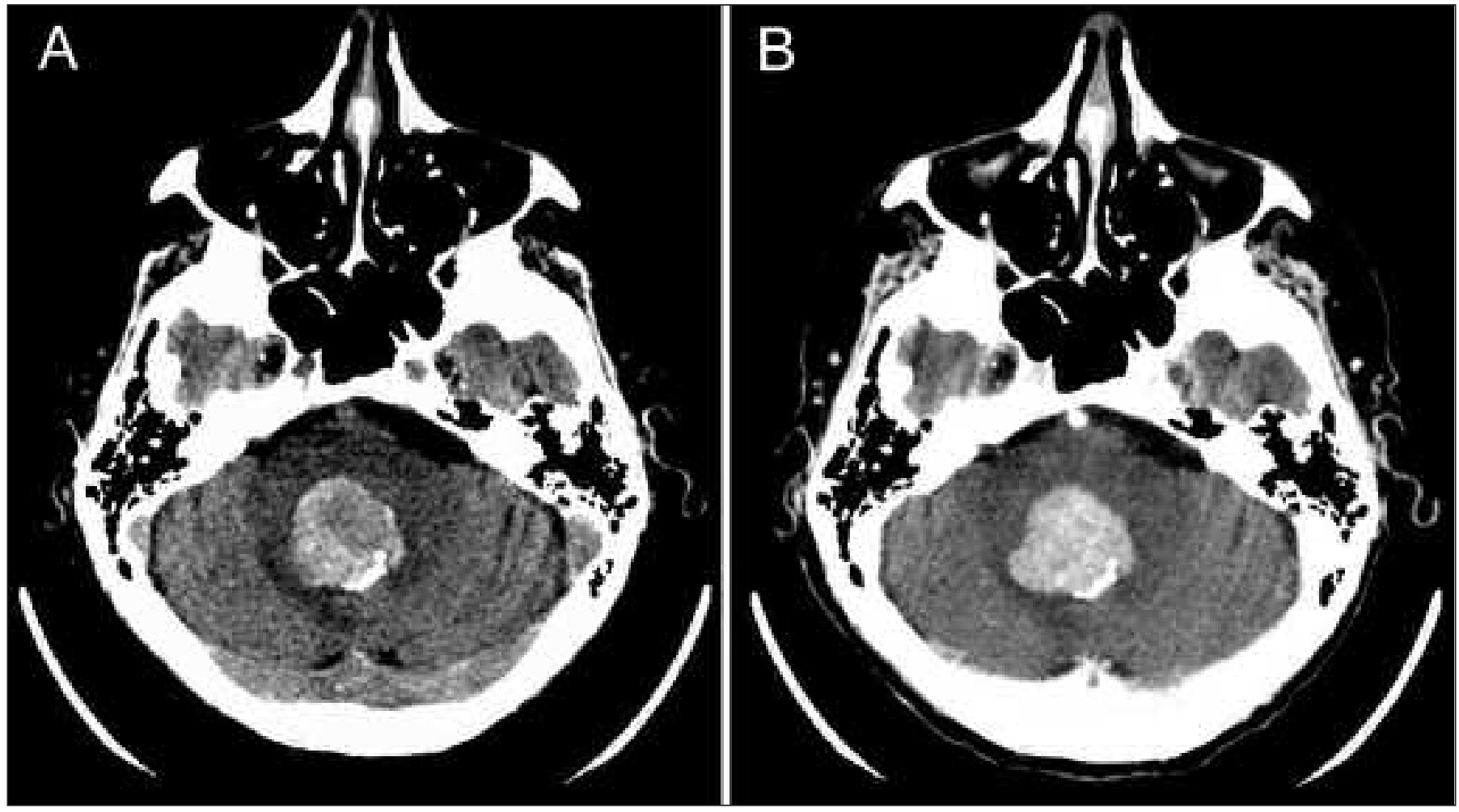

Figure 1: (A) Axial non-contrast CT brain shows a partially calcified hyperattenuating mass within the fourth ventricle. (B) Axial post-contrast CT brain shows avid enhancement within the tumour.

The patient described nausea and vomiting, but denied headache, urinary incontinence, or sensory symptoms. His past medical history was significant for hypertension and polycythemia rubra vera, which had been treated successfully with phlebotomy and hydroxyurea. Physical examination revealed bilateral sixth nerve palsies, dysarthria, dysmetria greater in the right arm than the left, and gait ataxia. The remaining cranial nerve, motor, and sensory examinations were normal.

A CT scan of the brain revealed a hyperattenuating, partially calcified, avidly enhancing mass within the fourth ventricle (Figure 1). An MRI scan of the brain demonstrated a mass within the fourth ventricle with heterogeneous signal characteristics (Figure 2A). Diffusion-weighted imaging showed restricted diffusion within the mass (Figure 2B). The differential diagnosis included ependymoma, atypical meningioma, choroid plexus papilloma, and metastasis. A metastatic screen including a chest radiograph, abdominal ultrasound, and liver function tests was negative.

The patient underwent a midline suboccipital craniotomy with ultrasound guidance for resection of the tumour. The tumour was situated within the fourth ventricle, had invaded the floor, and was purple-grey, soft in consistency, and highly vascular. Only a subtotal resection could be achieved due to the tumour's vascularity, which hindered adequate visualization of the tumour margins. Histological examination showed a densely cellular neoplasm composed of small cells with a high nuclear-to-cytoplasmic ratio, hyperchromatic nuclei and a tendency towards neuroblastic rosette formation (Figure 3A).
Most cells were strongly positive for neuron-specific enolase (Fig. 3B) and synaptophysin (Figure 3C). Ultrastructurally, tumour cells were poorly differentiated (Figure 4A) and showed evidence of neuronal differentiation in the form of aggregates of microtubules in the cytoplasm and cell processes (Figure 4B). These findings were consistent with a classical medulloblastoma.

Postoperatively, the patient's neurological examination was not significantly changed. An MRI of the entire spine was performed for staging purposes and was negative. He went on to receive 3600 cGy of external beam radiation therapy to the craniospinal axis in 20 fractions with a boost to the posterior fossa of $1800 \mathrm{cGy}$ in 10 fractions. Initially, treatment was tolerated well with only some mild nausea and vomiting, but the patient went on to develop subacute radiation encephalopathy eight weeks after the completion of radiation therapy, presenting with expressive dysphasia and worsened cerebellar symptoms. A follow-up MRI at this time revealed that the residual portion of the tumour within the right vermis had decreased moderately in size. The appearance of the tumour was stable at 24 weeks after the completion of radiation therapy and the patients symptoms had improved.

\section{DisCUSSION}

Medulloblastoma is rare in patients older than 50 years of age. $^{3}$ They are thought to be derived from remnants of the external granular layer of the cerebellum, cells of which may have a predisposition to neoplastic transformation early in life. ${ }^{4}$ 

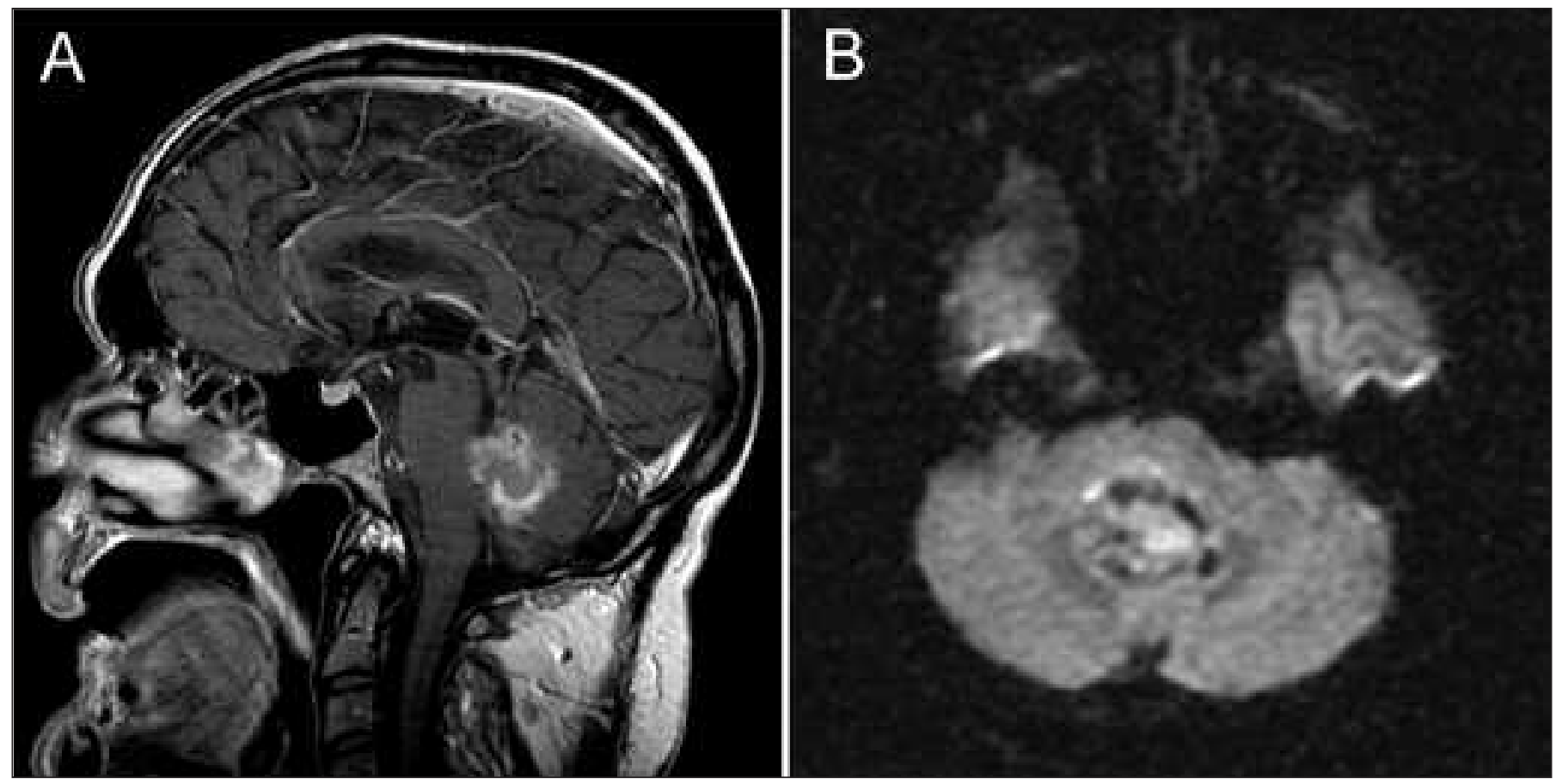

Figure 2: (A) Sagittal FLAIR sequence shows a mass within the fourth ventricle with heterogeneous signal characteristics. (B) Axial diffusion-weighted sequence demonstrates restricted diffusion within the tumour.

The oldest patient on record with clinical information was 73 at the time of diagnosis and had a cerebellar hemispheric medulloblastoma. ${ }^{5}$ To our knowledge, we report the oldest patient with a medulloblastoma of the fourth ventricle. Mechanisms of pathogenesis late in life are currently not known.

The signature imaging feature of medulloblastoma on noncontrast CT is hyperattenuation, reflecting the dense cellularity of these tumours on histological analysis. ${ }^{1}$ The dense cellularity of these tumours also results in restricted diffusion of free water, as illustrated via diffusion-weighted MRI. Treatment should consist of gross total resection if possible, ${ }^{6,7}$ early postoperative MRI for prognostication, and craniospinal radiation. ${ }^{8}$ Adjuvant chemotherapy may be useful in patients thought to be at high risk of recurrence, but the available evidence has not clearly demonstrated benefit. ${ }^{9}$ Collin's Law states that the period of risk of recurrence for embryonal tumours is nine months plus the age of diagnosis. ${ }^{10}$ According to this rule, our patient would certainly be at risk of recurrence for the remainder of his life. The application of Collin's Law, however, is only valid if theories of childhood medulloblastoma pathogenesis hold true for older
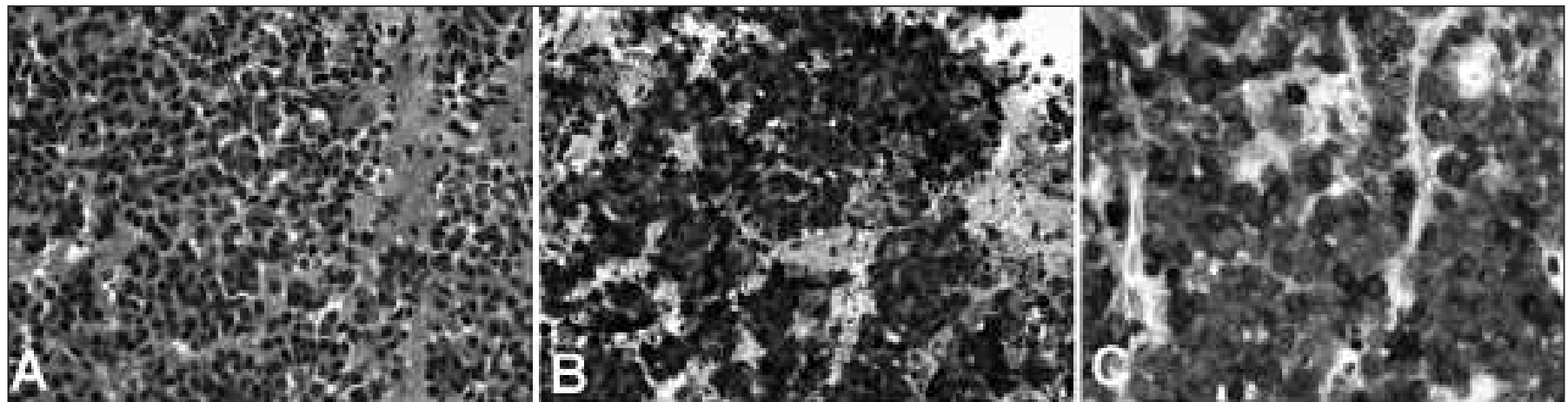

Figure 3: (A) The tumour is densely cellular and composed of small cells with round or ovoid nuclei and small amounts of cytoplasm arranged in clusters or solid sheets. There is a tendency for the tumor cells to aggregate around eosinophilic fibrillar areas hematoxylin and eogin (H+E). The majority of tumour cells show strongly positive cytoplasmic staining for neuron-specific enolase (B) and synaptophysin (C). A: 200x; B: 200x; C: 400x 


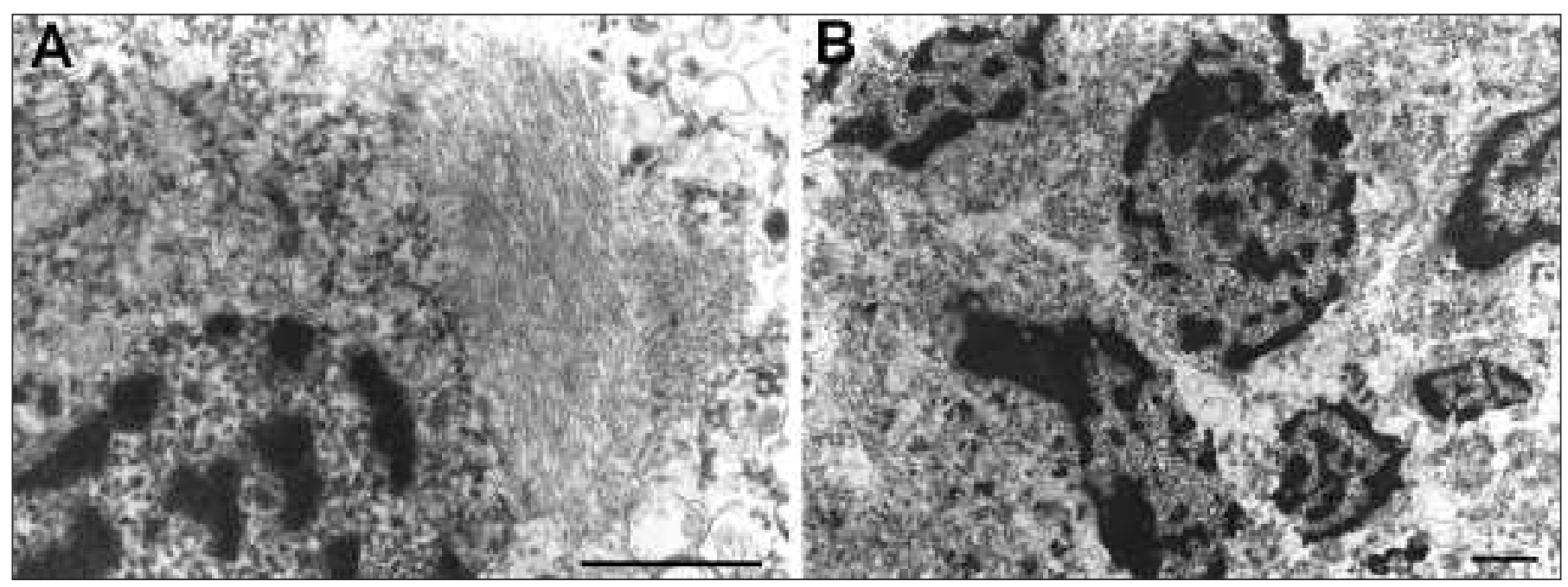

Figure 4: (A) Electron micrograph showing closely packed undifferentiated cells with scant cytoplasm, paucity of organelles, peripherally condensed chromatin and advanced degenerative changes. (B) Dense aggregates of microtubules are present in the cytoplasm of tumour cells. Bars $=1 \mu \mathrm{m}$.

patients. In any case, close follow-up with serial MRI for older patients with medulloblastoma is clearly warranted.

We conclude that adult medulloblastoma should be considered in the differential diagnosis of a partially calcified hyperattenuating mass within the fourth ventricle.

\section{REFERENCES}

1. Koeller KK, Rushing EJ. From the archives of the AFIP: Medulloblastoma: a comprehensive review with radiologicpathologic correlation. Radiographics. 2003; 23: 1613-37.

2. Hubbard JL, Scheithauer BW, Kispert DB, et al. Adult cerebellar medulloblastomas: the pathological, radiographic, and clinical disease spectrum. J Neurosurg. 1989; 70: 536-44.

3. Giordana MT, Schiffer P, Lanotte M, et al. Epidemiology of adult medulloblastoma. Int J Cancer. 1999; 80: 689-92.

4. Raaf J, Kernohan JW. Relation of abnormal collections of cells in posterior medullary velum of cerebellum to origin of medulloblastoma. Arch Neurol Pyschiatry. 1944; 52: 163-9.
5. Kepes JJ, Morantz RA, Dorzab WE. Cerebellar medullo-blastoma in a 73-year-old woman. Neurosurgy. 1987; 21: 81-3.

6. Gajjar A, Sanford RA, Bhargava R, et al. Medulloblastoma with brain stem involvement: The impact of gross total resection on outcome. Pediatr Neurosurg. 1996; 25: 182-7.

7. Bourne JP, Geyer R, Berger M, et al. The prognostic significance of post-operative residual contrast enhancement on CT scan in paediatric patients with medulloblastoma. J Neurooncol. 1992; 14: $263-70$.

8. Landberg TG, Lindgren ML, Cavallin-Stahl EK, et al. Improvements in the radiotherapy of medulloblastoma, 1946-1975. Cancer. 1980; 45: 670-8.

9. Brandes AA, Palmisano V, Monfardini S. Medulloblastoma in adults: clinical characteristics and treatment. Cancer Treat Rev. 1999; 25: 3-12.

10. Bloom HJG, Wallace ENK, Henk JM. The treatment and prognosis of medulloblastoma in children. AJR Am J Radiol 1969; 105: 43-62. 